\title{
Coordination in Supply Chains: From Case Studies to Reference Models
}

\author{
Yue Ming*, Raymond Houé, and Bernard Grabot \\ University of Toulouse, INPT, LGP-ENIT \\ 47, avenue d'Azereix, BP1629 \\ F-65016 Tarbes Cedex, France \\ \{yue.ming, rhoue, bernard\}@enit.fr
}

\begin{abstract}
Intensive competition has forced companies to focus on their core business and as a consequence to participate to more and more complex supply networks. The necessity to preserve the autonomy of each partner makes such networks usually managed in a decentralized way. Consequently, problems and conflicts emerge during the coordination processes. This paper describes some coordination problems identified through interviews and locates them within the activities of the coordination processes. Interpretations of the aspects influencing coordination are suggested, allowing to better explain the origins of these problems.
\end{abstract}

Keywords: Supply Chain; Coordination; Modeling; Performance.

\section{Introduction}

Nowadays, the growing intensive competition has forced enterprises to focus on their core business and participate in more and more complex Supply Networks (SNs). To build an efficient partnership, the crucial element is the coordination between partners, including selecting a suitable partner, executing and measuring the performance of coordination.

For years, various literatures have related efforts in giving mechanisms, models and tools of coordination in order to improve the overall performance of a supply chain. In the marketing literature, coordination mechanisms have mainly focused on pricing decisions, for instance linked to contract [1], demand [2] and advertising [3]. In the operations research literature, most of works on coordination of supply chain are related to the optimal process parameters and policy, such as inventory policy [4], delivery [5] or order processing [6]. Besides, works on tools and techniques for supporting coordination are widely presented, such as agent-based frameworks [7], attribute-based approach [8] or Virtual e-Chain [9]. Commonly, coordination in a supply chain can be interpreted as exchanging information, plans and executions which have been performed in isolation but may take into account the partner's constraints and expectations. Building a consistent coordination framework on that base is a

\footnotetext{
${ }^{*}$ Corresponding author.
} 
complex process, not only dealing with models and techniques but also related to other aspects, such as characteristics of partners, types of supply chains, or communication means. Marcotte et al. [10] suggest for instance coordination models based on the mutual influence of the partner and network. However, as a first step, it is critical to track the problems linked to the various activities of the cooperation process. Identifying possible dysfunctions, diagnosing reasons and tracing the resources which may facilitate coordination are basic but critical issues. This paper focuses on identifying real problems in coordination processes, based on case studies, and at identifying the causes of these problems.

The communication is organized as follows: in section 2, is introduced the background of the case studies. The typical structure of the Supply Networks of the interviewed companies is given. In section 3 are introduced two models giving an overview of the activities involved in typical cooperation processes and allowing to localize some coordination problems. We then list the aspects which influence coordination, in order to better explain the origin of these problems. In section 4, we propose two models that interpret the relationships according to these aspects in order to provide directions for a better cooperation.

\section{Case Studies in the Aeronautic Industry}

As stated above, more attention is usually paid to supply chain planning rather than to coordination models. Coordination processes are more than the juxtaposition of purchasing, production and delivery, which are the main operational processes in a supply chain. In order to approach real industry situations, we have conducted interviews in various contexts, all aiming at analyzing problems arising in the coordination between large and small companies belonging to supply chains in the aeronautic sector of the South-West region of France. Interviews in more than thirty companies of various sizes have allowed to identify a considerable list of problems, either linked to technical or behavioral issues [10],[11]. Only some of them will be discussed here.

From the case studies, it is first clear that the structure of a supply chain is in practice more complex than a unidirectional flow (see Figure 1): it also includes loops which may be the origin of internal conflicts. Usually, the coordination in the interviewed companies is managed at three levels, namely long term, middle term and short term. The long term coordination process focuses on the definition of the partnership and dimensioning of the chain without any detailed information. This long term process defines average flows and provides information for all the partners in the chain, while forecasts are exchanged at middle term in order to adjust the capacities. The short term level is more operational and includes information such as purchasing orders or production orders. However, uncertainty of forecast in the middle term process and urgent orders at short term induce much instability. The changes between different slide planning are also source of conflicts during coordination. Considering the case studies, it is apparent that managing partnerships and eliminate barriers are critical elements that indeed exist in each activity of coordination. Problems usually emerge during coordination since actors are sometimes focusing on their own interpretation and benefits, without consideration of a win-win mechanism which would sometimes require negotiation. This point will be addressed in next section. 


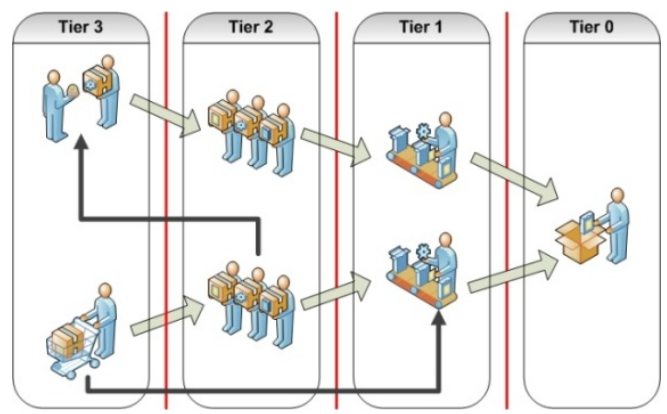

Fig. 1. Typical structure of a Supply Chain

\section{Qualitative Models of Coordination Processes}

Many models have already been suggested in the literature for describing logistic processes in supply chain (see SCOR [12], ASLOG [13], etc.), with the idea that applying these processes would allow increasing performance. We would like to show in this section that whenever the processes are "correct", problems may arise due to other aspects which are not included in these models. We have here used the ARIS [14] formalism for describing our process models.

\subsection{Long Term Coordination}

In the long term coordination process, the main activities can be identified as in Figure 2. When selecting a sub-contractor for a given long-term relationship, the customer defines its own standards, which are more and more elective. A result is that a multiplication of certifications is required from the sub-contractors, since standard certifications are often particularized by the customers to their own case. The customer also takes into account the results of his previous relationships with the sub-contractor, for instance through its key performance indicators (KPIs) (service ratio, etc.). As a consequence, the sub-contractors complain about the high cost and work induced by this over-assessment, which can in some cases hardly be linked to real performance.

Reaching a common agreement may be difficult since it usually includes not only conditions on price and cycle times, but a commitment for constantly decreasing these values through time. A problem often related is that the people involved at the customer's are more and more buyers, with a poor experience in technical aspects. Therefore, most of the discussion concern prices, which may induce at short term technical problems. Once the contract has been signed, the sub-contractor has to perform local adjustments (investments, contacts with its own sub-contractors or suppliers) for being able to execute the contact. The availability of efficient information systems and production management tools play an important role in making plans in long term, middle term and short term. Indeed, this complex task requires the subcontractor to be capable of processing forecasts from his customer, using his information tools and assessing risk due to forecast uncertainty. Tools are here an issue, but also the competence and motivation of sub-contractors for tasks that they consider as "administrative", not belonging to their core business. 


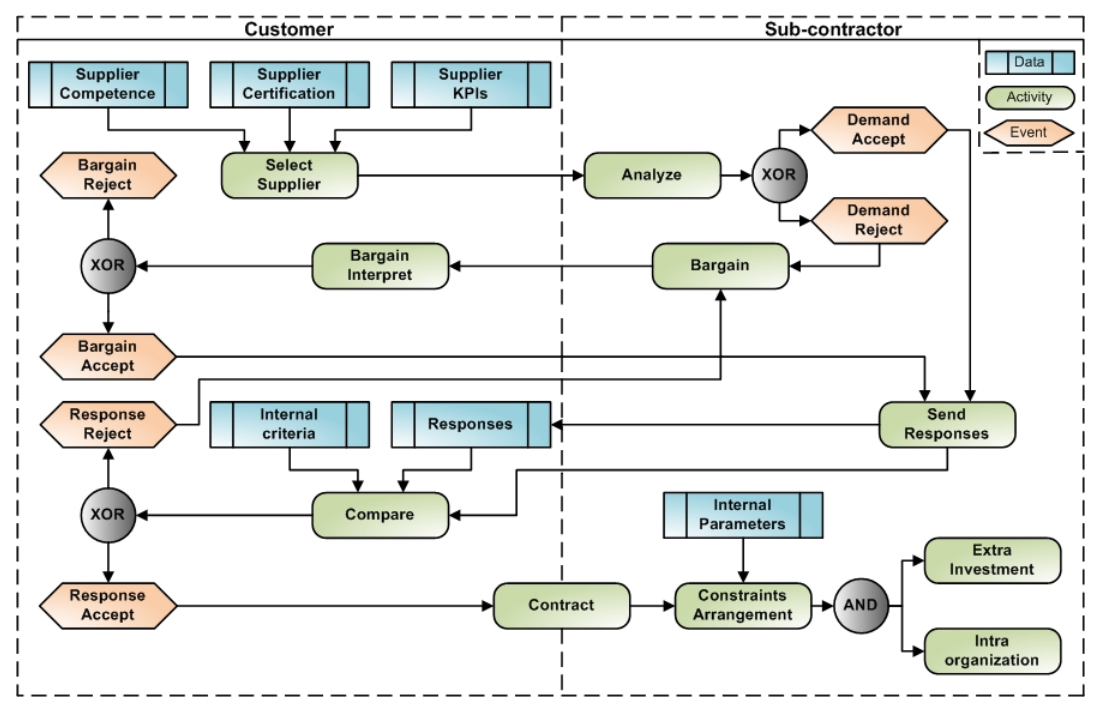

Fig. 2. Long term coordination process model

\subsection{Short Term Coordination}

In the short term coordination process (see Figure 3), the sub-contractor usually tries to improve its internal efficiency for being able to decrease its costs through time. This necessity makes that different orders having similar characteristics are often grouped, resulting in problems for meeting the due dates and decreasing the cycle times. In addition, planning is often disturbed by urgent orders or returned goods. In many cases, the urgency of the orders is questionable (and may rapidly change through time) while parts are often returned due to cosmetic reasons (aspect of the parts, not linked to functional issues), to over-tolerances or to different interpretations from the customer and the sub-contractor. On the other hand, sub-contractors often have some difficulty for performing their internal planning, and as a consequence for not being able to control their own suppliers. Therefore, it is very usual that a

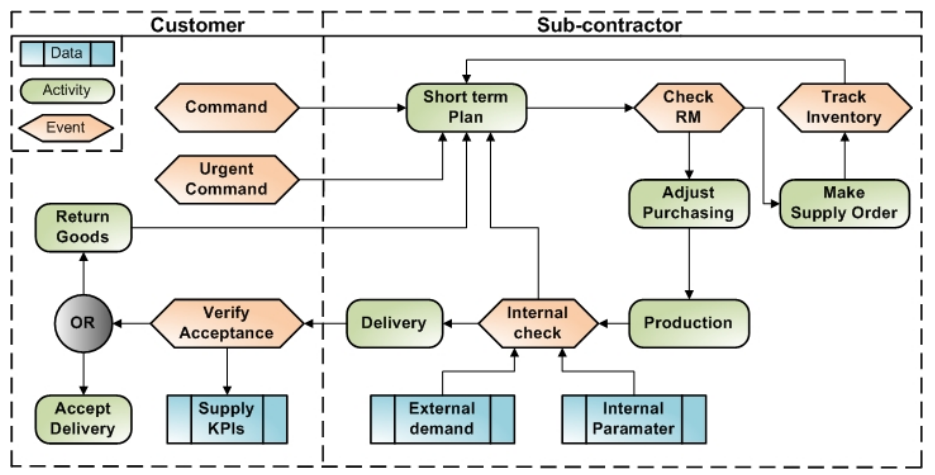

Fig. 3. Short term coordination process model 
sub-contractor only detects a problem concerning the availability of an order when the delivery has to be performed.

On the customer side, measure of performance indicators may become more important than good sense: several sub-contractors mentioned cases when their performance was good, but considered as poor according to the customer's performance indicators, and conversely.

\subsection{Concepts to be Added to the Coordination Models}

From the coordination models and the described problems, we suggest interpreting some influence aspects that impact the coordination performance and are not usually taken into account.

Trust. Trust is interpreted as the degree of partners' confidence in each other for accomplishing behaviors and achieving benefits as the agreements. In supply chain coordination, partners need to trust each other for exchanging internal information, such as purchase lead time, internal costs or inventory level. Both coordination actors are confident that exchanging information leads to better cooperation rather than losing confidential data or competitive advantages. In practice, trust has a strong influence in the cooperation processes since it allows each partner to share information and to have a positive view on the partner's behave.

Common Understanding. Common understanding is a kind of agreed interpretation between customers and sub-contractors, which is required in several issues in which misunderstanding often occur, like uncertainty of forecasts, urgency, standards of quality and etc.

Willing to Cooperate. As an individual entity that pursues benefits, enterprise, in certain case, chooses to concentrate on its own interests without the considerations of the overall chain. For instance, the customer sends a consultant to its sub-contractor in order to improve the supply performance. However, the consultant only pays attention to the works related to his employer, or even raises the priority of these works ignoring the overall plan of its sub-contractor. These self protective activates of the customer possibly reduce the willing of cooperate of the sub-contractor.

Balance of Power. Balance of power is a very important condition of cooperation in a supply chain, and may result from various issues: size of the partner, specialty (critical for the partner or not), power in the whole supplier chain, competence, access to markets etc.

It is clear that these aspects are interrelated. For instance, balance of power strongly impacts the communication atmosphere and accordingly influences common understanding between partners. We shall try in next section to investigate these relationships at a quite global level, and then try to correlate them with some of the problems observed during the case studies.

\section{Towards and Extended Model for Cooperation}

From the case studies, we introduce four main concepts that could be taken into account when considering the cooperation not only focusing on formalized processes 
but also tracing the influence issues of the conflicts. It is also apparent that these aspects are interrelated and relevant to certain cooperation processes. In this section, we suggest two simplified models to presents the relationships at a global view, from both the customer and the sub-contractor's points of view.

In Figure 4 are positioned the relationships between the concepts suggested in the previous section with the customer's point of view. A key point is that the customer has a very positive view on all his incentives towards his suppliers: for him, audits, certification, and competition with other suppliers are good means for increasing the motivation of the partner, and so its performance. Similarly, having a common understanding with the suppliers mainly comes from common standards, brought by certification. Balance of power is only of interest for allowing sharing risk, which is one of the ultimate goals of large companies within supply chains.

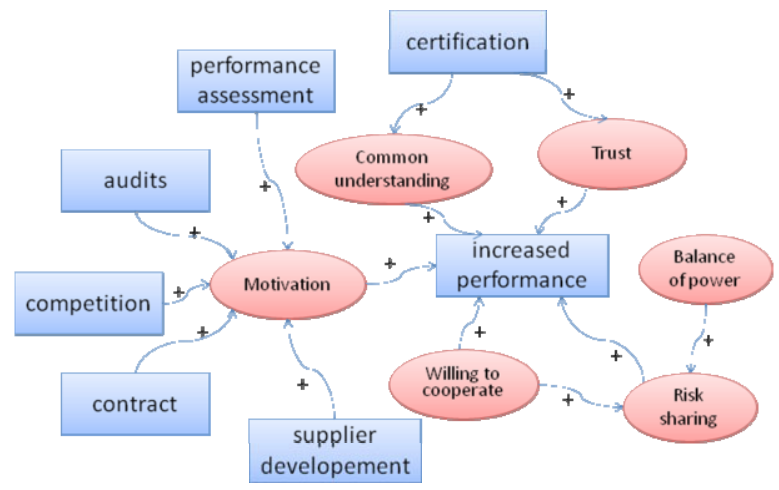

Fig. 4. Relationships between concepts - the customer's side

On the opposite, the same concepts are positioned in Figure 5 according to the subcontractor point of view. Most of the initiatives of the customer aiming at improving its maturity and motivation are considered as a proof of distrust, and have a negative influence on motivation and willing to cooperate. The idea of mutual respect is here of prime importance, since the small companies want to be recognized for their skills. This need for mutual respect is struck by the tentative of the customer to change their suppliers (in his view, "increase its maturity"). The origin of most of these misunderstandings is certainly in a lack of dialogue: in the customer's mind, standardization of the relationship leads to performance (through the use of common tools, common processes, etc.). For the small and medium enterprises, dialogue and actions are more important than standards. Balance of power is here only pursued in order to have an influence on the contracts, which is clearly not the idea of the large companies.

These two simplified models provide a first interpretation of the relationships between suggested concepts according to the interviews from the case studies. The results suggest that influence concepts that induce conflicts during the cooperation play opposite roles in different sides of partners. The same concepts which are considered as positives issues for cooperation in the customer's point of view are reversely treated as negative facts from the sub-contractor side. Only an increased dialogue could solve such an issue. 


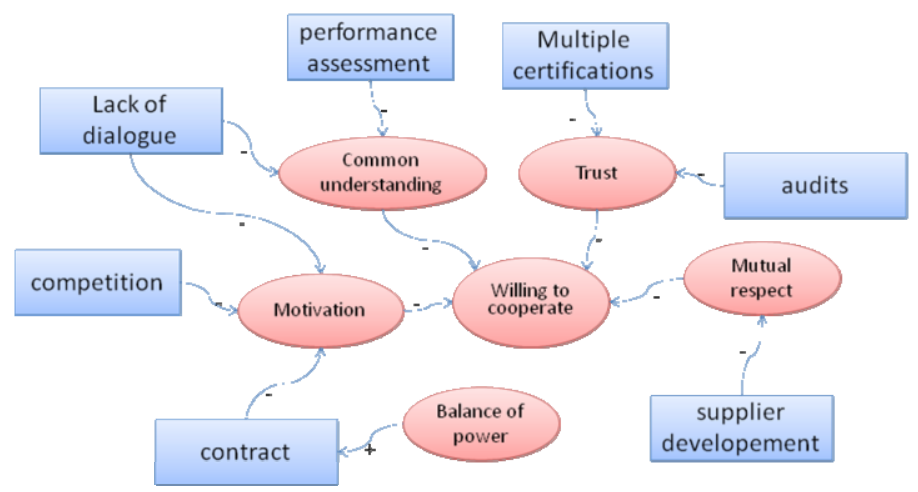

Fig. 5. Relationships between concepts - the sub-contractor's side

\section{Conclusion}

In this paper, we suggest reference models to describe the cooperation processes according to real case studies. These processes are close to the main activities described in existing models, such as SCOR etc. Accordingly, the purpose of proposed models is locating problems that may arise due to other aspects which are not included in the existing models. Then, we focus on interpreting the concepts that induce the cooperation problems allowing better explaining the origin of these problems. Based on the interpreted concepts, two models are proposed in order to draw attention to global view of relationships among these concepts and the relevance between concepts and cooperation processes.

Due to the case studies in aeronautical industry, the results from the reference models are approach to real cooperation situations, showing that problems during cooperation may be induced by interrelated non-technical concepts such as trust, common understanding, willing to cooperate, balance of power and so on, which are not considered in other models for supply chain cooperation. In addition, the same concepts which are considered as positive points for cooperation in the customer's side are in opposite considered as negative facts from the sub-contractor side. This is a key point that impacts the cooperation in supply chain.

As perspectives in future work, we suggest that cooperation models could consider these interrelated concepts as the "input" or "data" in order to improve the cooperation from partnership rather than standard processes. A possible way to ameliorate the proposed models using ARIS is that "data" are classified according to its influence to the customer and the sub-contractor. For instance, concept "trust" acts as a "support data" in the models of the customer, in opposite, "trust" plays as a "constraint data" in the models of the sub-contractor. In that way, both the customer and the subcontractor are legible about the conflicts and commons, furthermore to improve the cooperation between partners. 


\section{References}

1. Cachon, G.P., Lariviere, M.A.: Supply Chain Coordination with Revenue-Sharing Contracts: Strengths and Limitations. Management Science 51(1) (January 2005)

2. Qi, X.D., Bard, J.F., Yu, G.: Supply Chain coordination with demand disruptions. The International Journal of Management Science, Omega 32, 301-312 (2004)

3. Huang, Z.M., Li, S.X.: An Analysis of Manufacturer-Retailer Supply Chain Coordination in Cooperative Advertising. Decision Sciences 33(3) (2002)

4. Cachon, G.P., Zipkin, P.H.: Competitive and Cooperative Inventory Policies in a TwoStage Supply Chain. Management Science 45(7), 936-953 (1999)

5. Zimmer, K.: Supply Chain coordination with uncertain just-in-time delivery. International Journal of Production Economics 77, 1-15 (2002)

6. Li, J.L., Liu, L.W.: Supply Chain coordination with quantity discount policy. International Journal of Production Economic 101, 89-98 (2006)

7. Xue, X.L., Li, X.D., Shen, Q.P., Wang, Y.W.: An agent-based framework for supply chain coordination in construction. Automation in Construction 14, 413-430 (2005)

8. Xu, L., Beamon, B.M.: Supply Chain Coordination and Cooperation Mechanisms: An Attribute-Based Approach. Journal of Supply Chain Management 42(1), 4-12 (2006)

9. Manthou, V., Vlachopoulou, M., Folinas, D.: Virtual e-Chain (VeC) model for supply chain collaboration. International Journal of Production Economics 87(3), 241-250 (2004)

10. Marcotte, F., Grabot, B., Affonso, R.: Cooperation models for supply chain management. International Journal Logistics Systems and Management 5(1/2), 123-153 (2009)

11. Galasso, F., Mercé, C., Grabot, B.: Decision support framework for supply chain planning with flexible demand. International Journal of Production Research 47(2), 455-479 (2009)

12. SCOR 9.0 Reference Guide, http: / /www . supply-chain. org

13. Association française pour la logistique, http://www. aslog.org

14. Davis, R.: ARIS Design Platform: Advanced Processes Modeling and Administration. Springer, Heidelberg (2008) 